$16^{\text {th }}$ International Congress of Metrology, 06010 (2013)

DOI: $10.1051 /$ metrology/201306010

(c) Owned by the authors, published by EDP Sciences, 2013

\title{
Performance studies in micropipette calibration
}

\author{
Nelson Almeida a Elsa Batista, Eduarda Filipe \\ IPQ - Instituto Português da Qualidade, Rua António Gião, 2, 2829-513 Caparica, Portugal
}

\begin{abstract}
The measurement of small amounts of liquids is very important in fields like, health, chemistry, microbiology and genetics. The most common used instruments for delivery of liquids, in the order of the microliter, are micropipettes or piston pipettes, of fixed or variable volume, with positive or air displacement operation. The method used in the calibration of micropipettes is the gravimetric method, which is the determination of the delivered mass of distilled water, at a reference temperature of $20{ }^{\circ} \mathrm{C}$. This method is based on ISO 8655 and ISO 4787. In order to verify the influence of specific experimental details of the normalized procedure described in ISO 8655-6, several experimental tests were performed by the Volume Laboratory of The Portuguese Institute of Quality, namely: Angle variation of aspiration and delivery of liquid; Immersion depth of the tip; Aspiration and delivery velocity; Type of tip and Altitude. This study will allow the improvement of the calibration procedure of micropipettes and the harmonization of the results between laboratories.
\end{abstract}

\section{Introduction}

Micropipettes are instruments used to measure very small amount of liquid, in the order of the microliter. There are several types of piston pipette and they all work by applying a hand or mechanical pressure on a piston or plunger that is working over a fixed length in a cylinder, which forces a pre-determined volume of liquid out of the orifice of the micropipette.

There are two fundamental principles of micropipette operation: air displacement pipettes that have an aircushion that moves between the piston and the sample liquid, which aspirates and dispenses the sample and the positive-displacement systems that have an integrate piston in the micropipette tip coming into direct contact with the sample solution.

Pipetting is a skilled operation that requires proper training and practice to achieve consistent and accurate results [1]. The standard document ISO 8655/6 [2] describes the general procedure for the determination of the volume of micropipettes but there are several influence factors that are not explained in detail, namely: aspiration and delivery velocity, angle variation of aspiration and delivery of liquid, immersion depth of the tip, type of tip used and altitude.

In order to have comparable results and realistic uncertainty claims, calibration laboratories should consider these influence factors in there calibration procedures.

\subsection{Velocity of aspiration and delivery}

The velocity of aspiration and delivery of liquid can be an influence factor. Drawing up the piston too quickly can

\footnotetext{
a Corresponding author: nalmeida@ipq.pt
}

result in the introduction of air bubbles resulting in an error in the amount of liquid dispensed.

\subsection{Angle of aspiration and delivery}

When a micropipette is being calibrated or used it should be held in the vertical position when aspirating the liquid. Errors can occur if the instrument is used at an angle, more liquid will be aspirated due to the impact of hydrostatic pressure.

When delivering the liquid, one should touch the micropipette against the wall of receiving/weighing vessel at an angle of about $30^{\circ}$ to $45^{\circ}$, in order to favour the delivery of all the liquid in the tip.

\subsection{Immersion depth}

The depth to which the tip is immersed should also be controlled in order to prevent measurement errors.

The normal immersion depth is $3 \mathrm{~mm}$. If the tip is immersed too deeply into the liquid the results could be erroneously high. This is due to the fact that liquid could adhere to the tip and be transferred along with the aliquot in the tip. If the tip is not enough immersed, the air could be drawn into the tip leading to lower volume aspiration.

\subsection{Tips}

The micropipette tip is a key component of the micropipette dispensing system. Its shape, material properties and fit have a major impact on the accuracy of the dispensing process. It is only possible to achieve the maximum precision and reliability with micropipette tips 
following the manufacturer specifications in order to have an optimum connection between the micropipette and tip. If different types of tips are used in calibration and later in testing, the results may not be consistent with each other.

\subsection{Altitude influence}

Piston stroke micropipettes (air displacement) have an air-cushion which moves between the piston and the sample liquid, and which aspirates and dispenses the sample. With the decreasing atmospheric pressure the density of the air-cushion decreases, leading to a reduction in the dispensed volume of the micropipette.

If the dead volume and the capillary rise of the liquid column in the micropipette are known, the change in volume that results from calibration at a location X2 (with $p_{L, X 2}$ atmospheric pressure) compared to a location $\mathrm{X} 1$ (with $p_{L, X 1}$ atmospheric pressure) can be calculated using the following formula [3]:

$\Delta V=-V_{t} \times \rho_{w} \times g \times h_{w} \times\left(\frac{1}{p_{L, X 2}-\rho_{w} \times g \times h_{w}}-\frac{1}{p_{L, X 1}-\rho_{w} \times g \times h_{w}}\right)$

Where,

$\Delta V / \mu \mathrm{L}$ : Volume change that results in the calibration at location X1 over a location X2

$V_{t} / \mu \mathrm{L}$ : Volume of the air cushion

$\mathrm{g} /\left(\mathrm{m} / \mathrm{s}^{2}\right)$ : Acceleration of gravity

$h_{w} / \mathrm{m}$ : Rising height of the liquid column in the micropipette tip

$p_{L, X 1} / \mathrm{Pa}$ : Atmospheric pressure at location $\mathrm{X} 1$

$p_{L, X 2} / \mathrm{Pa}$ : Atmospheric pressure at location $\mathrm{X} 2$

$\rho_{w} /\left(\mathrm{kg} / \mathrm{m}^{3}\right)$ : Water density at X2

\section{Calibration method}

\subsection{Gravimetry}

The most used method in the calibration of micropipettes is the gravimetric one and consists on weighing the amount of water delivered from the micropipette. A conversion is then performed from mass to volume at a reference temperature of $t_{0}$ (normally $20^{\circ} \mathrm{C}$ ). Ten repeated measurements are performed and an average value obtained. The recommended equation is described in ISO 4787 [4] standard:

$$
V_{20}=\left(I_{L}-I_{E}\right) \times \frac{1}{\rho_{W}-\rho_{A}} \times\left(1-\frac{\rho_{A}}{\rho_{B}}\right) \times\left[1-\gamma\left(t-t_{0}\right)\right]+\delta V_{\text {evap }}+\delta V_{\text {rep }}
$$

\subsection{Calibration conditions and apparatus}

The ambient calibration conditions should be controlled and registered during calibration. The air temperature should be maintained between $17{ }^{\circ} \mathrm{C}$ and $23{ }^{\circ} \mathrm{C}$ and stable to $\pm 0,5^{\circ} \mathrm{C}$. Relative humidity should be above 50 $\%$. The apparatus and micropipettes should be allowed to stabilize in the laboratory before any work is carried out. Six hours is normally adequate for this.

An appropriated balance with appropriated measuring interval and resolution to the volume under calibration should be used. For these experiments it was used a balance with $20 \mathrm{~g}$ range of a nominal indication interval and $0,001 \mathrm{mg}$ resolution. An evaporation trap was installed in the balance plate in order to minimize evaporation.

A PT100 thermometer, with a resolution of $0,01{ }^{\circ} \mathrm{C}$ was used for the water temperature measurement. The used liquid was grade 2 pure water, according to ISO 3696 [5].

\subsection{Uncertainty calculation}

For the uncertainty calculation of the micropipettes calibration, it was used the GUM approach [6] with the mathematical model drafted at eq. 2. The identified uncertainty components and the correspondent evaluation are presented in Table 1.

Table 1. Uncertainty components for gravimetric calibration

\begin{tabular}{|c|c|c|c|}
\hline $\begin{array}{c}\text { Uncertainty } \\
\text { source }\end{array}$ & $\begin{array}{c}\text { Standard } \\
\text { uncertainty }\end{array}$ & $\begin{array}{c}\text { Evaluation } \\
\text { process }\end{array}$ & Distribution \\
\hline Mass & $u(m)$ & $\begin{array}{c}\text { Calibration } \\
\text { certificate }\end{array}$ & Rectangular \\
\hline $\begin{array}{c}\text { Density of } \\
\text { water }\end{array}$ & $u\left(\rho_{W}\right)$ & Literature & Rectangular \\
\hline Density of air & $u\left(\rho_{A}\right)$ & Literature & Rectangular \\
\hline $\begin{array}{c}\text { Density of the } \\
\text { mass pieces }\end{array}$ & $u\left(\rho_{B}\right)$ & $\begin{array}{c}\text { Calibration } \\
\text { certificate }\end{array}$ & Rectangular \\
\hline $\begin{array}{c}\text { Temperature } \\
\text { Expansion } \\
\text { coefficient }\end{array}$ & $u(\gamma)$ & $\begin{array}{c}\text { Calibration } \\
\text { certificate }\end{array}$ & Rectangular \\
\hline Evaporation & $u\left(\delta V_{\text {evap }}\right)$ & $\begin{array}{c}\text { Experimental } \\
\text { results }\end{array}$ & Rectangular \\
\hline Repeatability & $u\left(\delta V_{\text {rep }}\right)$ & $\begin{array}{c}\text { Standard } \\
\text { deviation }\end{array}$ & Normal \\
\hline
\end{tabular}

The combined standard uncertainty was determined using equation 3 :

$$
\begin{aligned}
u\left(V_{20}\right)= & {\left[\left(\frac{\partial V_{20}}{\partial m}\right)^{2} u^{2}(m)+\left(\frac{\partial V_{20}}{\partial \rho_{w}}\right)^{2} u^{2}\left(\rho_{w}\right)+\left(\frac{\partial V_{20}}{\partial \rho_{A}}\right)^{2} u^{2}\left(\rho_{A}\right)+\left(\frac{\partial V_{20}}{\partial \rho_{B}}\right)^{2} u^{2}\left(\rho_{B}\right)+\left(\frac{\partial V_{20}}{\partial \gamma}\right)^{2} u^{2}(\gamma)+\right.} \\
& \left.\left(\frac{\partial V_{20}}{\partial t}\right)^{2} u^{2}(t)+u^{2}\left(\partial V_{\text {equ }}\right)+u^{2}\left(\partial V_{\text {rep }}\right)\right]^{\frac{1}{2}}
\end{aligned}
$$

The expanded uncertainty is then obtained multiplying the combined standard uncertainty by a coverage factor $k$ determined for a level of confidence of $95 \%$ (normally $k=2$ ).

$U=k \times u\left(V_{20}\right)$ 
The values of the expanded uncertainty in the calibration of a micropipette, in good working conditions, can vary between $0,1 \%$ and $0,2 \%$.

\section{Experimental results}

The calibration of four micropipettes of different volumes: $10 \mu \mathrm{l}, 100 \mu \mathrm{l}, 1000 \mu \mathrm{l}$ e $10000 \mu \mathrm{l}$ was performed according to the reference conditions described in table 2 .

Table 2. Calibration reference conditions

\begin{tabular}{|c|c|}
\hline Reference conditions & Value \\
\hline Velocity of aspiration & $4 \mathrm{~s}$ \\
\hline Velocity of delivery & $4 \mathrm{~s}$ \\
\hline Angle of aspiration & $90^{\circ}$ \\
\hline Angle of delivery & $30^{\circ}$ \\
\hline Immersion depth & $3 \mathrm{~mm}$ \\
\hline Type of tip & Manufacturer \\
\hline Altitude & Sea level \\
\hline Uncertainty & $0,1 \%-0,2 \%$ \\
\hline
\end{tabular}

The reference conditions were then changed in order to identify the measurement errors associated with incorrect calibration procedures.

\subsection{Velocity of aspiration and delivery}

The calibration of the micropipettes was performed at two different velocities: $2 \mathrm{~s}-\mathrm{a}$ lower value than the reference, and $8 \mathrm{~s}$ - a higher value than the reference.

For the delivery and aspiration velocity the results are drafted at Tables 3 and 4:

Table 3. Delivery velocity measurement error (\%)

\begin{tabular}{|c|c|c|}
\hline $\begin{array}{c}\text { Measurement } \\
\text { Error (\%) }\end{array}$ & \multicolumn{2}{|c|}{ Delivery velocity } \\
\hline Micropipette & $2 \mathrm{~s}$ & $8 \mathrm{~s}$ \\
\hline $10 \mu \mathrm{l}$ & $-0,53$ & 0,27 \\
\hline $100 \mu \mathrm{l}$ & $-0,50$ & 0,10 \\
\hline $1000 \mu \mathrm{l}$ & $-0,04$ & 0,03 \\
\hline $10000 \mu \mathrm{l}$ & $-0,06$ & 0,10 \\
\hline
\end{tabular}

Table 4. Aspiration velocity measurement error (\%)

\begin{tabular}{|c|c|c|}
\hline $\begin{array}{c}\text { Measurement } \\
\text { Error (\%) }\end{array}$ & \multicolumn{2}{|c|}{$\begin{array}{c}\text { Aspiration } \\
\text { velocity }\end{array}$} \\
\hline Micropipette & $2 \mathrm{~s}$ & $8 \mathrm{~s}$ \\
\hline $10 \mu \mathrm{l}$ & $-0,02$ & 0,45 \\
\hline $100 \mu \mathrm{l}$ & $-0,20$ & 0,18 \\
\hline $1000 \mu \mathrm{l}$ & $-0,02$ & 0,26 \\
\hline $10000 \mu \mathrm{l}$ & $-0,10$ & 0,10 \\
\hline
\end{tabular}

From the analysis of the results it can be concluded that the velocity of micropipette handling is an influence factor in the accuracy of the micropipette calibration. The faster the handling the lower the volume delivered.

\subsection{Angle of aspiration and delivery}

The angle of delivery and aspiration of liquid was changed during calibration procedure.

For the delivery and aspiration angles the results are drafted at Tables 5 and 6 :

Table 5. Delivery angle measurement error (\%)

\begin{tabular}{|c|c|c|}
\hline $\begin{array}{c}\text { Measurement } \\
\text { Error (\%) }\end{array}$ & \multicolumn{2}{|c|}{ Delivery angle } \\
\hline Micropipette & $60^{\circ}$ & $90^{\circ}$ \\
\hline $10 \mu \mathrm{l}$ & $-0,10$ & $-0,20$ \\
\hline $100 \mu \mathrm{l}$ & $-0,10$ & $-0,20$ \\
\hline $1000 \mu \mathrm{l}$ & $-0,14$ & $-0,20$ \\
\hline $10000 \mu \mathrm{l}$ & $-0,05$ & $-0,19$ \\
\hline
\end{tabular}

Table 6. Aspiration angle measurement error (\%)

\begin{tabular}{|c|c|c|}
\hline $\begin{array}{c}\text { Measurement } \\
\text { Error (\%) }\end{array}$ & \multicolumn{2}{|c|}{$\begin{array}{c}\text { Aspiration } \\
\text { angle }\end{array}$} \\
\hline Micropipette & $45^{\circ}$ & $60^{\circ}$ \\
\hline $10 \mu \mathrm{l}$ & 0,21 & 0,08 \\
\hline $100 \mu \mathrm{l}$ & 0,18 & 0,03 \\
\hline $1000 \mu \mathrm{l}$ & 0,32 & 0,17 \\
\hline $10000 \mu \mathrm{l}$ & 0,46 & 0,13 \\
\hline
\end{tabular}

From the analysis of the results it can be concluded that changing the delivery angle will result in a volume 
decrease and changing the aspiration angle will result in a volume increase.

\subsection{Immersion depth}

In order to test the results of the micropipette calibration by changing the immersion of the tip in the water two different experiences were performed, at $1 \mathrm{~mm}$ depth and at $6 \mathrm{~mm}$ depth. The results are the following:

Table 7. Immersion depth measurement error (\%)

\begin{tabular}{|c|c|c|}
\hline $\begin{array}{c}\text { Measurement } \\
\text { Error (\%) }\end{array}$ & \multicolumn{2}{|c|}{ Imersion depth } \\
\hline Micropipette & $1 \mathrm{~mm}$ & $6 \mathrm{~mm}$ \\
\hline $10 \mu \mathrm{l}$ & $-0,34$ & 0,10 \\
\hline $100 \mu \mathrm{l}$ & $-0,10$ & 0,20 \\
\hline $1000 \mu \mathrm{l}$ & $-0,10$ & 0,15 \\
\hline $10000 \mu \mathrm{l}$ & $-0,10$ & 0,24 \\
\hline
\end{tabular}

At $1 \mathrm{~mm}$ depth the results are lower because air enters the system. When the tip is immersed too deeply into the liquid, $6 \mathrm{~mm}$, the results are higher than the reference due to the fact that liquid could adhere to the tip and be transferred to the weighing vessel.

\subsection{Tips}

Two different types of tips were used in the calibration of the three micropipettes, one of the manufacturer (reference value) and another from a different brand. The results are the following:

Table 8. Tip measurement error (\%)

\begin{tabular}{|c|c|c|c|}
\hline Micropipette & $\begin{array}{c}\text { Measurement } \\
\text { Error (\%) }\end{array}$ & $\begin{array}{c}\text { Manufacturer } \\
\text { tip diameter } \\
\text { (mm) }\end{array}$ & $\begin{array}{c}\text { Other } \\
\text { brand } \\
\text { tip } \\
\text { diameter } \\
\text { (mm) }\end{array}$ \\
\hline $10 \mu \mathrm{l}$ & $+1,48 \%$ & 5,05 & 5,00 \\
\hline $100 \mu \mathrm{l}$ & $+0,16 \%$ & 5,05 & 5,00 \\
\hline $1000 \mu \mathrm{l}$ & $+0,70 \%$ & 7,70 & 7,65 \\
\hline
\end{tabular}

Both tips have a very similar design but the tip from the other brand has a smaller diameter and the fitting is at a lower point of the micropipette than the manufacturer tip. This means that the displaced volume or air is larger than for the tip of the manufacturer leading to higher liquid volume delivered.

\subsection{Altitude influence}

The following figure can be obtained using the results of the international comparison CCM.FF.K4.2.2011 [6] related to the calibration of $100 \mu \mathrm{l}$ micropipettes with air displacement principle:

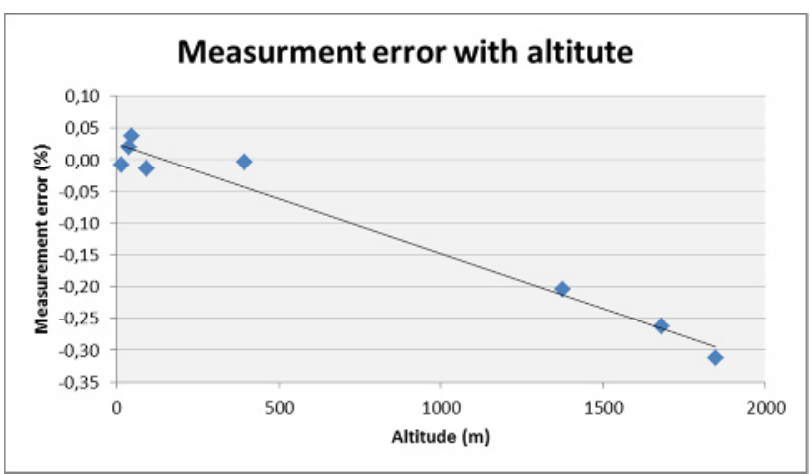

Figure 1. Measurements error with altitude

From the results we can see that there is a relation between altitude and the measurement error in micropipettes of air displacement. The higher the altitude the lower the volume delivered and therefore this effect must always be corrected if the laboratory is working at high altitude.

\section{Conclusion}

The calibration of micropipettes requires a detailed measurement procedure and the work of experienced metrologists.

There are several experimental factors that can influence both calibration and use of micropipettes and some of them were studied in this work. After analyzing the results, it can be concluded that lower volumes are obtained if the delivery angle is larger than $30^{\circ}$ and also if the laboratory is working at high altitudes. Higher volumes can be obtained if the aspiration of the liquid is not performed at an angle $90^{\circ}$ and the micropipette is immersed too deeply into the liquid.

Calibration laboratories should take care of these experimental factors in their calibration procedures in order to have comparable results, since this information is not drafted at the ISO standard 8655 .

We can conclude also from this study that in order to have more realistic results, the uncertainty of the method variability and reproducibility should be considered as uncertainty components and included in the uncertainty budget.

\section{References}

1. Batista, E., Filipe, E., Mickan, B: Volume calibration of $1000 \mu \mathrm{l}$ micropipettes. Inter-laboratory comparisons, Accredited Quality Assurance, 13, (2008)

2. ISO 8655:2002 - Piston-Operated volumetric apparatus 
3. ISO 4787:2010 - Laboratory Glassware - Volumetric Glassware - Methods for use and Testing of Capacity

4. ISO 3696:1987 - Water for analytical laboratory use Specification and test methods

5. GUM - JCGM 2008, Evaluation of measurement data - Guide to expression of uncertaity in measurement, 1st ed., (2008)

6. Calibration guide DKD-R 8-1; calibration of piston pipettes, (2011) 